\title{
Seabirds mated for life migrate separately to the same places: behavioural coordination or shared proximate causes?
}

\author{
Martina S. Müller ${ }^{\text {a, }}{ }^{*}$, Bruno Massa ${ }^{\text {b }}$, Richard A. Phillips ${ }^{c}$, Giacomo Dell'Omo ${ }^{d}$ \\ ${ }^{a}$ Graduate School of Environmental Studies, Nagoya University, Nagoya, Japan \\ ${ }^{\mathrm{b}}$ University of Palermo, Department of Agriculture and Forest Sciences, Palermo, Italy \\ ${ }^{\text {c } B r i t i s h ~ A n t a r c t i c ~ S u r v e y, ~ N a t u r a l ~ E n v i r o n m e n t ~ R e s e a r c h ~ C o u n c i l, ~ C a m b r i d g e, ~ U . K . ~}$ \\ d Ornis italica, Rome, Italy
}

\section{A R T I C L E I N F O}

\section{Article history:}

Received 23 October 2014

Initial acceptance 12 December 2014

Final acceptance 20 January 2015

Published online

MS. number: 14-00856

\section{Keywords:}

behavioural strategy

carryover effects

global location sensor

GLS logger

inbreeding

mate fidelity

movement ecology

partner coordination
Long-term pair bonds occur in diverse animal taxa, but they are most common in birds, and can last from a few years to a lifetime. In many of these species, after the reproductive season, birds migrate to distant nonbreeding grounds where they remain for several months, and until recently, little was known about whether partners maintain contact during migration. This gap in knowledge was primarily due to past methodological difficulties in tracking long-term, large-scale movements of individuals. However, the development of new animal-borne geolocation devices has enabled researchers to track movements of individuals for a year or more. We tracked the annual migrations of both members of breeding pairs of Scopoli's shearwaters, Calonectris diomedea, breeding on Linosa Island (Italy) and found that although they did not migrate together, they did spend a similar number of days travelling to and from similar terminal nonbreeding areas. Although migration destinations were alike, they were not identical. That partners did not appear to travel or spend time together in the nonbreeding season suggests that similarities were not due to behavioural coordination. We performed additional analyses to uncover alternative, potential proximate mechanisms. First, we found that body mass of breeding adults during the chick-rearing period correlated positively with the decision to migrate further south, so conceivably pair members may migrate to similar areas because of shared reproductive costs; however, partners were not of similar body mass. Distances between nonbreeding areas for individuals that nested closer together were smaller than for individuals that nested far apart. As neighbours tend to be more closely related due to high natal philopatry, this suggests that similarities within pairs in migration behaviour may reflect the influence of shared genes on migration strategy.

() 2015 The Association for the Study of Animal Behaviour. Published by Elsevier Ltd. All rights reserved.
Animals form long-term breeding partnerships in diverse species including invertebrates (Seibt \& Wickler, 1979), fish (Fricke, 1986) and mammals (Clutton-Brock, 1989), but most commonly in birds (reviewed in Black, 1996). Pair bonds in birds often endure for several years (in ca. $50 \%$ of bird orders, $21 \%$ of bird families; Black, 1996), and can last for life, particularly in long-lived species (Bried \& Jouventin, 2002; Hamer, Schreiber, \& Burger, 2002). In these species, losing or changing a mate carries substantial energy and opportunity costs associated with finding a new partner and breeding site (Bried \& Jouventin, 2002), and often results in a missed breeding season. Furthermore, breeding attempts of reunited partners tend to be much more successful than those of

\footnotetext{
* Correspondence: M. S. Müller, Graduate School of Environmental Studies, Nagoya University, 1 Furo-cho, Chikusa-ku, Nagoya 464-8601, Japan.

E-mail address: martina.muller9@gmail.com (M. S. Müller).
}

new partners (Coulson, 1970; Mills, 1979; Chardine, 1986; Ollason \& Dunnet, 1988; Black, 1996, 2001; Van de Pol, Heg, Bruinzeel, Kuijper, \& Verhulst, 2006; Limmer \& Becker, 2010; SánchezMacouzet, Rodríguez, \& Drummond, 2014), indicating that experience with the same mate fine-tunes partner compatibility (the 'mate familiarity effect'; Black, 1996). High mate fidelity and behavioural coordination between partners is particularly pronounced in seabirds (Bried \& Jouventin, 2002; Hamer et al., 2002) and probably evolved because they live for a long time, and successful reproduction requires biparental care during both incubation and chick rearing (Clutton-Brock, 1991; Wittenberger \& Tilson, 1980; Hamer et al., 2002). Seabirds must therefore carefully coordinate key aspects of their behaviour with those of their partner, including the timing of trips to sea (which affects the distances and locations to which they can travel), to ensure the successful execution of reproductive duties that include defending the nest site, incubating eggs or caring for chicks (Clutton-Brock, 1991; 
Hamer et al., 2002). Indeed, more behaviourally synchronized pairs tend to achieve higher breeding success (e.g. Hatch, 1990; Hamer et al., 2002).

Soon after breeding, however, most seabirds leave the breeding colony and migrate long distances to spend the nonbreeding period in regions with seasonally higher prey availability and a milder climate (Berthold, 2001; Hamer et al., 2002; Pulido, 2007). As they have a strong incentive to maintain their pair bond from one year to the next, partners may have an advantage if they could coordinate their migration schedules to travel together, maintain contact in nonbreeding areas, or at least return to the colony at the same time during the prebreeding period. Alternatively, pairs may show similarities in migration behaviour without actively coordinating their behaviour, for example if other shared traits (e.g. genetic or life history) influence migration.

Until recently, however, little was known about whether, in pelagic seabirds, long-term partners travel together, meet in nonbreeding areas or show other similarities in migration behaviour (but see Ens, Choudhury, \& Black, 1996). This is mainly because, historically, most migration research depended on ring resighting, a powerful method for mapping the general movements of species and populations but limited in utility for following the detailed movements of individuals. New tracking technology, however, permits the tracking of birds' movements in detail for an entire year or longer, making it possible to follow the migration journeys of both pair members (Phillips, Silk, Croxall, Afanasyev, \& Bennett, 2005; Schaffer et al., 2006; Guilford et al., 2009, 2012; Rayner et al., 2012). These data can reveal whether partners depart, travel or return at similar times, or go to the same destinations.

Here we report spatial and temporal characteristics of the annual migration of mated adult Scopoli's shearwaters, Calonectris diomedea, in the winters following successful breeding seasons. The aim of our study was two-fold: (1) to determine whether partners show similarities in migration behaviour, and (2) to assess whether any similarities reflect active behavioural coordination, and if not, whether they could be indirect effects of other traits shared by partners, such as similarity in body size or condition, or nest placement in the breeding colony. This is, to our knowledge, the first study to report detailed analyses of similarities among pair members in temporal and spatial aspects of migration, and to investigate the proximate drivers.

\section{METHODS}

\section{Instrument Deployment}

The Scopoli's shearwater is a pelagic seabird that breeds in the Mediterranean, formerly classified as a subspecies of the Cory's shearwater but now considered to be a separate species (Sangster et al., 2012). Our study population breeds on Linosa island $\left(35^{\circ} 87^{\prime} \mathrm{N}, 12^{\circ} 86^{\prime} \mathrm{W}\right)$, which holds the second largest breeding colony of Scopoli's shearwaters in the Mediterranean (ca. 10000 breeding pairs; see Massa \& Lo Valvo, 1986). The nests are located mostly in the crevices of the ca. $1 \mathrm{~km}$ long lava formations along the northern coast of the volcanic island, in an area called Mannarazza. Breeding females lay a single egg during the second half of May, chicks hatch around mid-July and fledglings leave the colony around the middle to end of October. Mate fidelity is high in this species (71.4-88.1\%: Mougin, Jouanin, \& Roux, 2000; Thibault, 1994; Cachia Zammit \& Borg, 1986; Swatschek, Ristow, \& Wink, 1994). About two-thirds of mate changes are due to an absent mate and only one-third reflect a divorce (Mougin et al., 2000).

We attached light-level global location sensors (MK9 from British Antarctic Survey, Cambridge, U.K., and MK3006 from Biotrack, Dorset, U.K.; hereafter GLS) to leg rings of adult breeding
Scopoli's shearwaters in 2009, 2010 and 2011, during the chickrearing period (early August). We recovered the instruments at the beginning of the subsequent breeding season (mid-May). We tracked 46 individuals from 31 nests for up to three nonbreeding seasons, which provided 60 complete migrations. Twelve individuals were tracked repeatedly: 10 individuals (six males, four females) for 2 years and two individuals (one male, one female) for 3 years. We obtained paired tracks (i.e. complete tracks from both members of a pair in the same year) at 16 nests; at six of these nests, both pair members were tracked twice or more. All of the tracks were of birds that successfully reared a chick to fledging, i.e. they were of similar breeding status. We distinguished between the sexes using body measurements (Lo Valvo, 2001) and vocalizations.

\section{Analysis of Geolocation Data}

The light data were processed using BASTrak software (British Antarctic Survey). We used a light threshold of 2 and a sun elevation angle of -5 , derived from calibration data from five geolocators of the same type left in the colony during the whole migration period. We visually inspected light transitions at sunrise and sunset, and assigned a level of confidence (scored from 1 to 9 , with 9 as the highest) based on the slope and smoothness of the light curve; only locations derived from the highest quality transitions (scored as 9 , which included more than $95 \%$ of transitions) were used in further analysis. Outward migration began in late October (after the autumn equinox) and the return migration ended in early February to mid-March (before the spring equinox), so there was no need to remove positions during equinox periods. Latitude and longitude were calculated from daylength and the timing of local noon, respectively. These geolocators provide two locations per day (at local midnight and noon) with an estimated mean error \pm SD of $186 \pm 114$ km (Phillips, Silk, Croxall, Afanasyev, \& Briggs, 2004).

\section{Migration Parameters}

We extracted several parameters that described different aspects of the birds' migration journeys, including the timing of movements, as well as spatial attributes such as locations of nonbreeding areas and distances and duration of travel. Periods of migratory flight were defined as those in which the bird travelled at least 0.8 degrees in one direction for at least three consecutive positions (1.5 days). A threshold value of 0.8 was chosen to identify half days during which birds travelled longer distances, because, in nonbreeding areas, birds moved on average only 0.02 degrees each half day in both longitude and latitude, compared with a mean of $>1.5$ degrees in longitude or latitude during migrations. Occasionally, birds appeared to travel a distance of $>0.8$ degrees during the nonbreeding period, which may indicate an excursion or random error in the location data; these could be excluded from the analysis because they did not satisfy the criterion that birds had to travel in the same direction for three consecutive positions.

The total time spent in transit during migration was the sum of all periods of flight during the migration period. Nonbreeding periods were defined as those in which birds ceased rapid directional flight for at least 3 days. We defined the number of days spent in nonbreeding areas as the time away from the colony that was not spent in transit. The final nonbreeding location was the last nonbreeding area in which birds spent time before they initiated the return (spring) migration. We determined the date and approximate time \pm ca. $6 \mathrm{~h}$ (as there are two locations per day) when birds (1) initiated migration in autumn (date of departure), (2) arrived at the first nonbreeding area, (3) initiated the return migration to the breeding colony from the 
terminal nonbreeding area in spring, and (4) arrived back in the breeding colony (date of return). We defined the total duration of migration as the interval between the dates of departure from and return to the colony. The total distance travelled was calculated as the sum of: (1) the distances between consecutive locations when birds were in transit between the breeding site and nonbreeding areas; (2) the distances of transit between nonbreeding areas if birds visited more than one nonbreeding area; and (3) the distance between point of entry and exit of each nonbreeding area. We also determined the southernmost point during migration (minimum latitude), which represents the terminal nonbreeding area and the most distal location from the colony. Finally, we computed the centroids of each of the nonbreeding areas from the latitude and longitude of the individual locations.

\section{Body Measurements}

All adults were weighed when the GLS were attached $(N=60)$ and for several we also measured culmen length (hereafter referred to as 'bill length', $N=33$ ). For the latter 33 birds, we calculated scaled mass index (SMI) as a measure of body condition, which represents the predicted body mass for individual $i$ when the body size measurement is standardized to $L_{0}$ (Peig \& Green, 2009). SMI is computed as $M_{i} \cdot\left[L_{0} / L_{i}\right]_{\text {SMA }}^{b}$ where $M_{i}$ is the body mass, $L_{i}$ is the bill measurement, $L_{0}$ is the arithmetic mean of $L_{i}$ and $b_{\mathrm{SMA}}$ is the scaling exponent (calculated by dividing the slope by the Pearson correlation coefficient).

\section{Nest Measurements}

We measured the distances between all nests of tracked individuals to assess whether nest proximity was related to variation in migration behaviour. In seabird colonies, breeding sites are found in clusters (Jovani \& Tella, 2007) and most spatial variation in nest quality and microenvironment is likely to be at this scale. We measured the distances between each nest included in our study and all the active nests in the colony within a $50 \mathrm{~m}$ radius. We calculated the surrounding nest density within each of five $10 \mathrm{~m}$ wide concentric bands radiating from each focal nest. We then calculated mean nest densities and 95\% confidence intervals, within $10 \mathrm{~m}, 20 \mathrm{~m}, 30 \mathrm{~m}, 40 \mathrm{~m}$ and $50 \mathrm{~m}$ of each nest. Nest density was higher within the first $10 \mathrm{~m}$ radius around each nest than at increasing distances, indicating clustering at this scale (mean nest density $\pm 95 \%$ confidence interval, $\mathrm{CI}: \quad 10 \mathrm{~m}$ radius: $0.038 \pm 0.017$ nests $/ \mathrm{m}^{2} ; \quad 20 \mathrm{~m}$ radius: $0.010 \pm 0.010$ nests $/ \mathrm{m}^{2} ; \quad 30 \mathrm{~m}$ radius: $0.007 \pm 0.005$ nests $/ \mathrm{m}^{2}$; $40 \mathrm{~m}$ radius: $\quad 0.006 \pm 0.001$ nests $/ \mathrm{m}^{2} ; \quad 50 \mathrm{~m}$ radius: $0.005 \pm 0.001$ nests $/ \mathrm{m}^{2}$ ). Distances between the nests of all tracked adults were then categorized within $10 \mathrm{~m}$ (hereafter referred to as 'same cluster') versus beyond $10 \mathrm{~m}$ (hereafter referred to as 'different cluster').

Shearwaters are known for their extremely high natal philopatry; they rarely disperse $>100 \mathrm{~m}$ from the site at which they fledged (Rabouam, Thibault, \& Bretagnolle, 1998). This species also shows extremely high nest site fidelity, and in the rare instances that adults change site, they usually move $<8 \mathrm{~m}$, and hardly ever move $>100 \mathrm{~m}$ (Thibault, 1994). Therefore, proximity in the breeding colony within a $100 \mathrm{~m}$ radius can act as a proxy for genetic relatedness, which may be reflected in the migration strategy. As variation in distances $<100 \mathrm{~m}$ may not be meaningful in terms of genetic relatedness, we also created a binary variable for nest distance, categorized $\leq 100 \mathrm{~m}$ (scored as 0 , hereafter referred to as 'neighbours') or $>100 \mathrm{~m}$ (scored as 1 , hereafter referred to as 'nonneighbours').

\section{Quantifying Similarities}

Repeatability $(r)$, also known as the intraclass correlation coefficient, is the proportion of the variance accounted for by differences within compared with between groups (discussed in detail in Lessells \& Boag, 1987; Nakagawa \& Schielzeth, 2010). It is used frequently for quantifying similarities among members of a group or multiple observations from the same subject. A statistically significant repeatability value indicates that differences within groups are relatively small compared to differences between groups. We calculated repeatability for mated pairs in migration parameters and body measurements using between-group variance and within-group variance components obtained from linear mixed models (LMM) using restricted maximum likelihood (Nakagawa \& Schielzeth, 2010). To produce the appropriate variance components, we performed LMMs that included Sex as a fixed factor and Nest, Individual and Year as random factors. Although we were interested in the variance in migration parameters explained by the Nest, we included the additional random factors to avoid inflating Nest repeatability estimates that were due to variation attributable to year differences or to the similarity among observations from the same individuals (Müller, Massa, Phillips, \& Dell'Omo, 2014). Then, we divided the between-nests variance component by the sum of the between-group and within-group variances to compute repeatability (Nakagawa \& Schielzeth, 2010). We determined statistical significance of repeatability by bootstrapping (Faraway, 2006; Nakagawa \& Schielzeth, 2010) using 1000 simulated iterations.

The distances between the centroids of each nonbreeding area were calculated for all tracked individuals ( $N=1750$ comparisons). To test whether these distances were smaller among pair members than among randomly paired individuals, they were included as the response variable in an LMM that included three random factors (identity of both individuals, and a binary variable indicating whether they were of the same or different sex) and a binary fixed factor indicating whether they were from the same or a different nest.

To explore whether similarities in migration characteristics among pair members were due to body size or condition, or associated with spatial structure in the breeding colony, we tested a series of models. The first series of LMMs included the migration parameter as the response, Mass and Sex as fixed factors, and Individual as a random factor. Sex was included to account for sex differences in body mass, as males are heavier than females. To confirm this sex difference, we performed an LMM predicting Mass with Sex, including Individual as a random factor. LMMs of the same migration parameters were repeated, with SMI as the predictor and Individual as a random factor. Sex was not included in these models, as the body condition index should have accounted for differences between sexes. To confirm that SMI did not differ between the sexes, we performed an LMM predicting SMI with Sex, and including Individual as a random factor.

To determine whether nest proximity was related to migration behaviour, we computed differences in the values of each parameter between all migration journeys of all birds (except those by the same individuals). These differences were included in LMMs with the categorical variable that reflected whether nests were from the 'same cluster' or a 'different cluster' (see above), and with the identities of both individuals included as random factors. We also performed three LMMs with body measurements (mass, bill length and SMI) as response variables, cluster category as a factor and the identities of both individuals in the comparison as random factors. The models for mass and bill length also included an additional, binary random factor indicating whether comparisons were of members of the same or different sex. In addition, we used LMMs to 
test whether migration parameters were related to the distances between nest sites, using 'neighbours' versus 'non-neighbours' (see above) as a fixed factor and the identities of both individuals as a random factor. In all models testing for the effect of nest proximity, we excluded comparisons within the same individuals that had been tracked multiple times and between members of the same pair.

\section{Relationships Among Migration Parameters}

To understand the relationships among the different migration parameters, we performed a series of LMMs using the complete data set from all 60 migrations. In all models, we included Individual, Nest and Year as random factors, with the southernmost point reached during migration (i.e. location of terminal nonbreeding area) included as the predictor. Finally, we tested for differences in the variances of each migration parameter using $F$ tests. All analyses were performed using $\mathrm{R}$ (version 2.12.1, R Development Core Team 2010). LMMs were performed using the lmer function in the lme4 package (Bates, Maechler, Bolker, \& Walker, 2014), and significance was determined using the lmerTest package (Kuznetsova, Brockhoff, \& Christensen, 2014).

\section{Ethical Note}

The geolocators used in our study weighed $2.5 \mathrm{~g}$, which is $0.55 \%$ of the mass of the lightest individual ( $450 \mathrm{~g}$ ) and $0.42 \%$ of the average mass of birds used in the study (mean mass $\pm \mathrm{SE}$ is $598.5 \pm 9.0 \mathrm{~g}$ ). This represents a small load for this species, particularly as the average mass of a single meal delivered to the chick is usually $15-20 \%$ of the adult's mass (e.g. Ricklefs, 1984; Ochi, Oka, \& Watanuki, 2010), and adult body mass can vary by $>100 \mathrm{~g}$ over the course of the breeding season (Ochi et al., 2010; Becciu, Massa, \& Dell'Omo, 2012). Furthermore, several recent studies of shearwaters reported no negative effects of GLS attachment on feeding success or any sign of injury to the leg (Yamamoto et al., 2011), nor evidence for compromised breeding success (Igual et al., 2005) or survival (Dias, Granadeiro, Phillips, Alonso, \& Catry, 2012). Finally, a recent comprehensive meta-analysis found no deleterious effects of GLS deployment on birds with body sizes as large as shearwaters (Costantini \& Møller, 2013).

In our study, birds were removed from their nest, weighed and measured, the GLS was attached to the leg ring and then the bird was returned to the nest burrows within $10 \mathrm{~min}$ of initial capture. All deployments occurred during a period when chicks were wellgrown and not vulnerable to minor disturbance. All monitoring, ringing and instrument deployment were approved by the Regione Siciliana, Assessorato Agricoltura e Foreste, Prot. 65887 dated 23 July 2007 and Prot. 17233 dated 1 December 2010.

\section{RESULTS}

\section{Overall Migration Route, Nonbreeding Locations and Phenology}

All individuals left Linosa during 18 October-18 November, travelled through the Strait of Gibraltar along the western coast of Africa to the Mauritanian continental shelf. Many birds (45\% of the migrations tracked) continued south along the African coast, and $15 \%$ travelled as far as the Benguela Upwelling region off Namibia. Birds arrived in the first nonbreeding area between 26 October and 9 December, departed on the spring migration back to the breeding site in 18 January-2 March, and arrived back in Linosa between 7 February and 27 March.

\section{Similarities in Migration Behaviour Among Pair Members}

Pair members showed a high degree of similarity in several migration parameters. In general, repeatability within pairs was higher for parameters associated with the location of nonbreeding areas (in particular, the southernmost latitude that was reached) than those that reflected timing of movements (Table 1, Fig. 1a, see Supplementary material for maps showing the complete migrations of all pairs). Pair members also spent a similar amount of time in transit to, from and between their nonbreeding areas (Table 1 , Fig. 1b). Repeatability within pairs was marginally nonsignificant for the total distance travelled during migration, and the time spent in nonbreeding areas (Table 1). Furthermore, a comparison of distances between all nonbreeding areas for all birds indicated that those of paired birds were closer to each other than to those of unpaired birds (paired: $b=-0.454, \mathrm{SE}=0.157, t=-2.90$, $P=0.004)$. There was no significant repeatability within pairs in the total duration of the nonbreeding period (Table 1) or in the timing of migration: pair members did not leave the breeding site together in autumn, arrive at the first or leave the last nonbreeding area together, nor return on similar dates in the spring (Table 1).

In summary, we found significant repeatability within pairs in migration parameters that were spatial, indicating that partners travelled to similar destinations. In contrast, timing of migration showed no significant repeatability within pairs, and differed sufficiently in most cases for it to be clear that partners did not spend the nonbreeding period or travel together, and therefore did not actively coordinate their migratory movements.

\section{Does Partner Similarity Correspond to Destination Similarity?}

There was no significant repeatability in body mass of pair members at the time of GLS deployment $(r<0.001, P=0.838$, $N=60$ ) or in body condition (SMI: $r<0.001, P=0.473, N=33$ ). As expected, males were heavier than females $(b=85.33, \mathrm{SE}=15.35$, $t=5.559, P<0.001, N=60$ ), but the sexes did not differ in SMI $(b=20.13, \mathrm{SE}=22.9, t=0.876, P=0.391, N=33)$. Differences in body mass or condition between birds did not show a significant relationship with distance between nonbreeding areas (Table 2). Smaller differences in bill length between birds, however, were associated with smaller distances between their nonbreeding areas, although the effect was weak (Table 2, Fig. 2).

Body mass at deployment showed a significant positive relationship with the total distance travelled during the migration period (Table 2, Fig. 3), and a marginally nonsignificant positive relationship with the total time spent in transit during migration (Table 2). However, body mass was unrelated to the location of the terminal nonbreeding area (southernmost point reached; Table 2). There was no significant relationship between SMI (body

Table 1

Repeatability $(r)$ and associated $P$ value in migration characteristics within breeding pairs of Scopoli's shearwaters

\begin{tabular}{clll}
\hline & Migration parameter & $r$ & $P$ \\
\hline Timing of & Date of departure from breeding site (autumn) & 0.42 & 0.483 \\
travel & Date of arrival at first nonbreeding area & 0.00 & 0.583 \\
& Date of departure from last nonbreeding area & 0.37 & 1.000 \\
& Arrival date to breeding site (spring) & 0.03 & 0.379 \\
Duration & Total duration of migration (days) & 0.00 & 0.811 \\
& Time spent in nonbreeding areas (days) & 0.29 & 0.057 \\
& Time spent in transit during migration (days) & 0.40 & $\mathbf{0 . 0 2 7}$ \\
Destination & Southernmost point reached (minimum latitude) & 0.51 & $\mathbf{0 . 0 0 9}$ \\
& Total distance travelled during migration (km) & 0.27 & 0.059 \\
\hline
\end{tabular}

Tests corrected for Sex (fixed factor), Individual and Year (random factors). Bold values indicate statistical significance $(\alpha=0.05)$. 

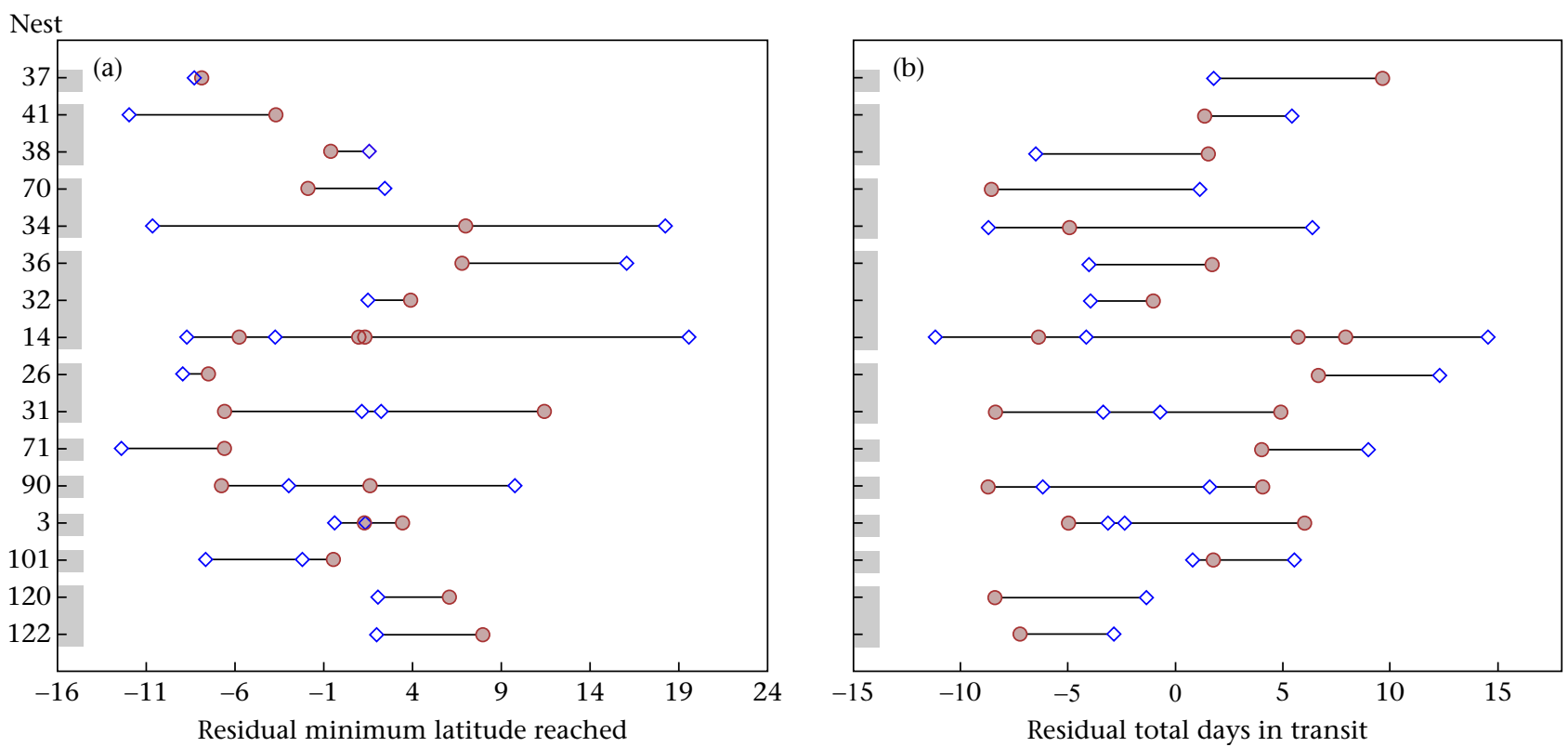

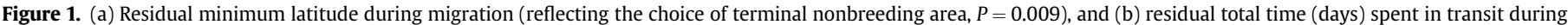

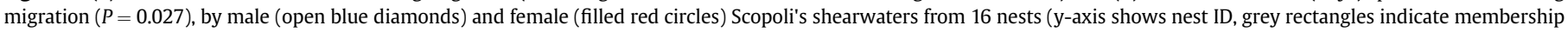
of the same nest cluster) tracked using GLS loggers in one to three consecutive nonbreeding seasons.

condition) and any migration parameter (Table 2) or with bill length (Table 2).

\section{Does Internest Distance Relate to Migration Characteristics?}

We found no evidence that migration characteristics of birds were related to whether they were from the same cluster (nests within $10 \mathrm{~m}$ ) or a different cluster (nests $>10 \mathrm{~m}$ apart) (Table 3 ). Nor was whether or not they were from the same cluster related to

Table 2

Linear mixed models of relationships between migration parameters and body measurements

\begin{tabular}{llccc}
\hline & & Mass & Bill length & SMI \\
\hline Minimum latitude & $b$ & -0.024 & -0.015 & 0.011 \\
& SE & 0.035 & 1.606 & 0.057 \\
& $t$ & -0.69 & -0.01 & 0.19 \\
Total time in transit (days) & $P$ & 0.496 & 0.993 & 0.850 \\
& $N$ & 60 & 33 & 33 \\
& $b$ & 0.066 & 0.485 & 0.000 \\
Total distance travelled (km) & SE & 0.034 & 1.799 & 0.052 \\
& $t$ & 1.92 & 0.27 & -0.01 \\
& $P$ & 0.060 & 0.791 & 0.992 \\
& $N$ & 60 & 33 & 33 \\
& $b$ & 51.840 & 220.200 & 30.940 \\
& SE & 16.510 & 862.210 & 21.650 \\
& $t$ & 3.14 & 0.26 & 1.43 \\
& $P$ & $\mathbf{0 . 0 0 3}$ & 0.801 & 0.167 \\
& $N$ & 60 & 33 & 33 \\
& $b$ & 0.001 & 0.086 & -0.001 \\
& SE & 0.001 & 0.038 & 0.001 \\
& $t$ & 1.35 & 2.25 & -1.15 \\
& $P$ & 0.177 & $\mathbf{0 . 0 3 3}$ & 0.251 \\
& $N$ & 1750 & 488 & 488 \\
\hline
\end{tabular}

Birds were weighed at the time of geolocator deployment. SMI represents scaled mass index, which is an index of body condition, using bill length as the structural size measurement. For the first three migration parameters, all models included Individual ID as a random factor, and the models including Mass also corrected for Sex (male shearwaters are larger than females). For 'locations of nonbreeding areas', all birds were compared to each other and differences in body measurements showed a significant association with differences in nonbreeding areas. IDs of both individuals in the comparison were included as random factors.

Bold values indicate statistical significance $(\alpha=0.05$ ) differences in body mass $(b=2.084, \mathrm{SE}=2.285, t=0.912$, $P=0.362, \quad N=1718)$, bill length $(b=-0.00001, \quad \mathrm{SE}=0.016$, $t=-0.001, P=0.999, N=466)$ or SMI $(b=4.665, \mathrm{SE}=5.755$, $t=0.811, P=0.418, N=466)$. Distances between nonbreeding areas of 'neighbours' (nests $<100 \mathrm{~m}$ ) were smaller than those of 'non-neighbours' (nests $>100 \mathrm{~m}$; Table 3, Fig. 4), but 'neighbours' and 'non-neighbours' did not differ in the southernmost point reached during migration, total time spent in transit or the total distance travelled during the migration period (Table 3 ).

\section{Relationships Among Migration Parameters}

Birds that travelled further south spent more time in transit, covered a longer cumulative distance, were absent from the

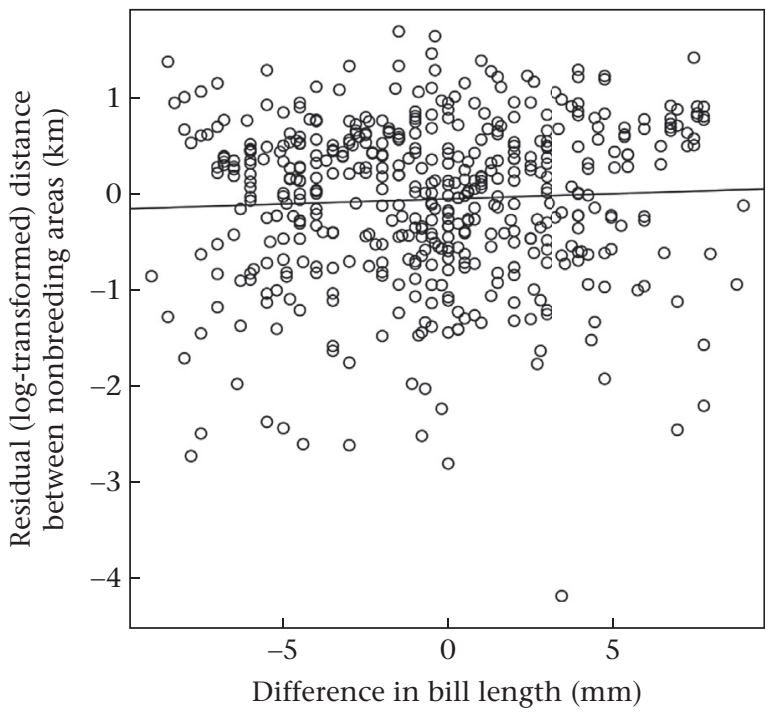

Figure 2. Residual average (log-transformed) distance between nonbreeding areas ( $y$ axis) in relation to difference in bill length (x-axis) of Scopoli's shearwaters, after accounting for whether birds were of the same sex, and also the ID of both individuals in the comparison (random factors), for $N=488$ comparisons $(P=0.033)$. 


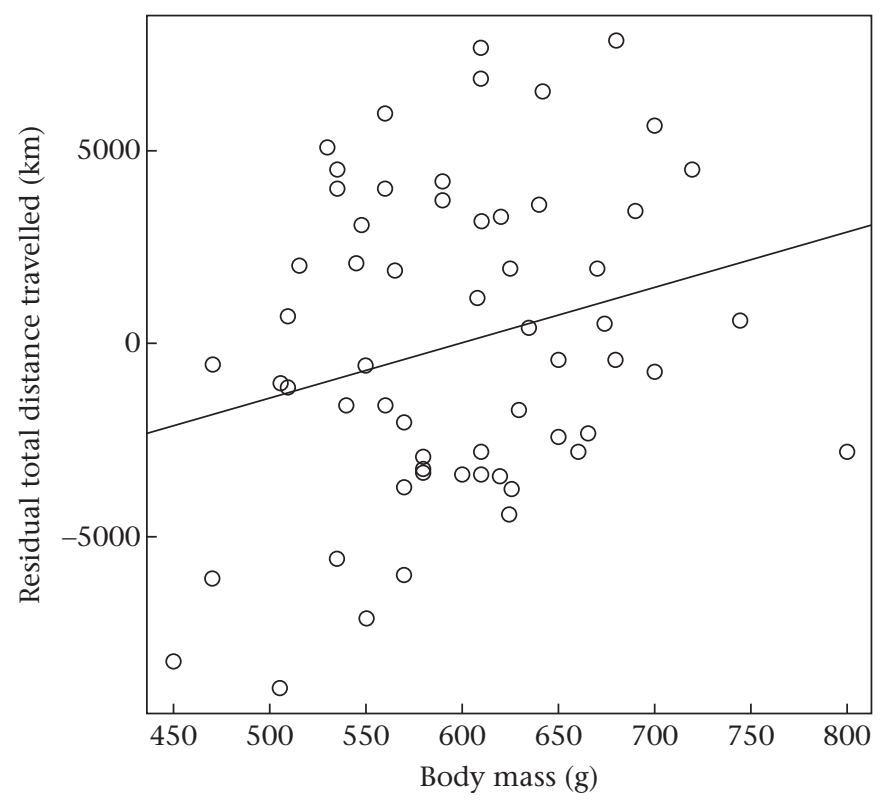

Figure 3. Residual total distance travelled during migration (y-axis) in relation to body mass at geolocator deployment (x-axis), after correcting for sex (fixed factor) and individual ID (random factor), for 60 migration journeys of Scopoli's shearwaters $(P=0.003)$.

breeding site for longer and returned later to the colony in the spring (Table 4). Dates of arrival at the first nonbreeding area and of departure from the final nonbreeding area were later for birds that travelled further south, and these individuals also spent significantly less time in nonbreeding areas (Table 4). Birds that travelled further south did not anticipate their longer journey by leaving the colony earlier (Table 4); indeed, the variance in departure date from the colony (23.26 days) was much smaller than that in arrival date at the first nonbreeding area (91.22 days; $F=3.921, P<0.001)$. This increased variance (i.e. reduced synchronicity) in timing of movements carried over to the later stages of migration: variance in date of arrival at the first nonbreeding area was similar to that in departure from the last nonbreeding area (85.64 days; $F=1.065$,

\section{Table 3}

Relationships between distances between nest sites of all birds tracked in this study (excluding partners) and differences in their migration parameters examined using linear mixed models

\begin{tabular}{clcc}
\hline & & $\begin{array}{c}\text { Same cluster } \\
(<10 \mathrm{~m})\end{array}$ & $\begin{array}{c}\text { Same neighbourhood } \\
(<100 \mathrm{~m})\end{array}$ \\
\hline Minimum latitude & $b$ & -0.640 & -0.005 \\
& $\mathrm{SE}$ & 0.660 & 0.006 \\
Total time in & $t$ & -0.97 & -0.95 \\
transit (days) & $P$ & 0.332 & 0.340 \\
& $b$ & 0.448 & -0.149 \\
Total distance travelled & $\mathrm{SE}$ & 0.530 & 0.493 \\
& $t$ & 0.85 & -0.30 \\
& $P$ & 0.398 & 0.763 \\
Locations of & $\mathrm{SE}$ & -0.245 & 0.145 \\
nonbreeding areas & $t$ & -0.425 & 0.395 \\
& $P$ & 0.564 & 0.37 \\
& $b$ & -0.037 & 0.714 \\
& $\mathrm{SE}$ & 0.081 & 0.164 \\
& $t$ & -0.46 & 0.073 \\
& $P$ & 0.643 & 2.23 \\
& & $\mathbf{0 . 0 2 6}$
\end{tabular}

In the first column, distances were categorized as $\leq 10 \mathrm{~m}$ (same cluster) or $>10 \mathrm{~m}$ (different cluster). In the second column, distances were categorized as $\leq 100 \mathrm{~m}$ (neighbours) or $>100 \mathrm{~m}$ (non-neighbours). IDs of both individuals in the comparison were included as random factors.

Bold values indicate statistical significance $(\alpha=0.05)$.

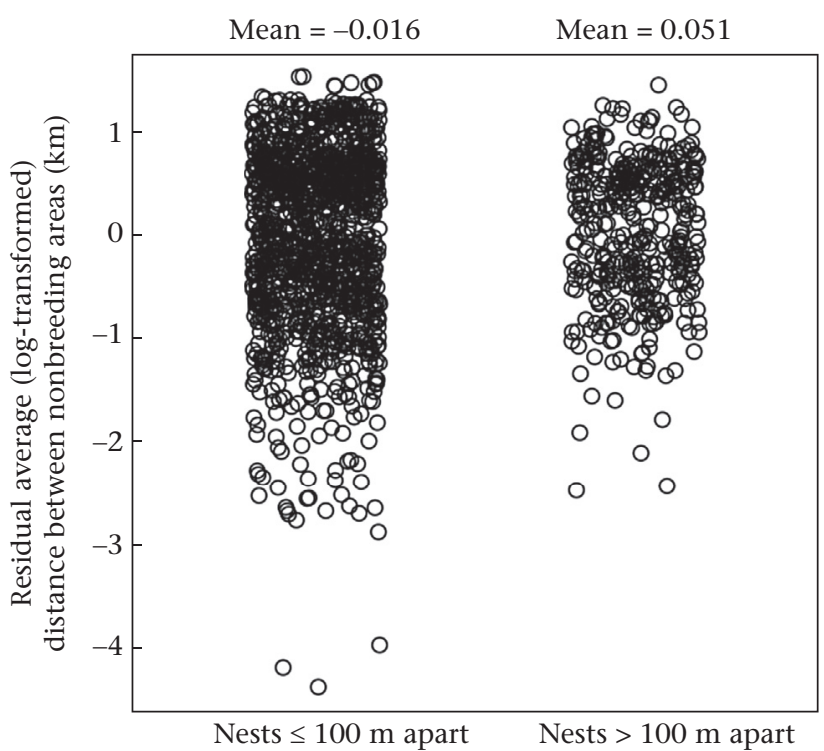

Figure 4. Residual average (log-transformed) difference between nonbreeding areas between birds ( $\mathrm{y}$-axis) in relation to distance between nests (x-axis), after correcting for ID of both individuals in the comparison (random factors), for $N=1718$ comparisons $(P=0.026)$.

$P=0.405)$ and in arrival date back at the colony (105.11 days; $F=1.227, P=0.217)$. This is because these latter parameters reflect how far south the birds had travelled during their migrations.

\section{DISCUSSION}

In this study we present the first detailed analysis of the migrations of both members of established breeding pairs of a pelagic seabird and show that partners travelled to broadly the same terminal nonbreeding destinations (Fig. 1a). We also showed that partners spent a similar number of days in transit to and from nonbreeding areas (Fig. 1b). Also, the distances between nonbreeding areas of paired individuals were smaller than among unpaired birds. The migration parameters that were significantly repeatable within pairs (terminal latitude, and total time spent in transit) were themselves highly correlated. Terminal nonbreeding latitude also correlated with the total distance travelled, which was marginally repeatable within pairs.

Terminal latitude was related to the date of return to the breeding site, indicating that the further south that birds travelled, the later they returned to the colony in spring. Partner synchrony in arrival at the breeding site after migration has been reported for black-tailed godwits, Limosa limosa islandica, in Iceland (Gunnarsson, Gill, Sigurbjornsson, \& Sutherland, 2004). In addition, GLS tracks of black-browed albatrosses, Thalassarche melanophris, showed a trend for pair members to arrive on similar dates to waters near the breeding colony at South Georgia (Phillips et al., 2005). In paired Chatham petrels, Pterodroma axillaris, males arrived first, females joined them within 1-4 days, and the pair subsequently remained together at the nest for 1-3 days, presumably mating (Rayner et al. 2012). Synchronized returns may therefore facilitate the renewal of the pair bond after a long separation during the nonbreeding period. In our study, however, even though partners travelled to similar latitudes, and although terminal latitude correlated overall with return date to the breeding site, we found no correspondence among partners in the date of return to the breeding site in spring. However, Scopoli's shearwaters have strong nest site fidelity (Thibault, 1994; Bried \& Jouventin, 
Table 4

Relationships between the southernmost points reached during migration and other migration characteristics

\begin{tabular}{|c|c|c|c|c|c|}
\hline & Migration parameter & $b$ & SE & $t$ & $P$ \\
\hline \multirow[t]{4}{*}{$\begin{array}{l}\text { Timing of } \\
\text { travel }\end{array}$} & $\begin{array}{l}\text { Date of departure from breeding } \\
\text { site (autumn) }\end{array}$ & 0.00 & 0.04 & -0.01 & 0.994 \\
\hline & $\begin{array}{l}\text { Date of arrival at first } \\
\text { nonbreeding area }\end{array}$ & -0.18 & 0.08 & -2.21 & 0.031 \\
\hline & $\begin{array}{l}\text { Date of departure from last } \\
\text { nonbreeding area }\end{array}$ & -0.21 & 0.08 & -2.66 & 0.01 \\
\hline & $\begin{array}{l}\text { Date of arrival at breeding } \\
\text { site (spring) }\end{array}$ & -0.31 & 0.07 & -4.32 & $<0.001$ \\
\hline \multirow[t]{3}{*}{ Duration } & Total duration of migration (days) & -0.31 & 0.08 & -3.96 & $<0.001$ \\
\hline & $\begin{array}{l}\text { Time spent in nonbreeding } \\
\text { areas (days) }\end{array}$ & 0.31 & 0.09 & 3.39 & 0.001 \\
\hline & $\begin{array}{l}\text { Time spent in transit during } \\
\text { migration (days) }\end{array}$ & -0.67 & 0.10 & -6.40 & $<0.001$ \\
\hline Destination & $\begin{array}{l}\text { Total distance travelled during } \\
\text { migration }(\mathrm{km})\end{array}$ & -318.82 & 44.37 & -7.19 & $<0.001$ \\
\hline
\end{tabular}

All models included Sex as a fixed factor, and Year, Individual and Nest as random factors ( $N=60$ journeys).

Bold values indicate statistical significance $(\alpha=0.05)$.

2002), which seems likely to be the primary mechanism facilitating their reunion in spring, rather than the timing.

Individuals travelling further south did not anticipate their longer return journey by leaving the breeding site earlier in autumn. All the birds tracked in our study followed a similar migration route in autumn along the west coast of Africa (Müller et al., 2014; see also Supplementary material); hence, even individuals that travelled further south (e.g. to Namibia or South Africa) passed the closer staging areas (Canary Islands, Cape Verde Islands, Guinea basin) en route to their final destination. As shearwaters often forage while they migrate (Dias et al., 2012), the tracked bird may have made facultative decisions en route concerning whether to remain in a particular area or travel further, depending on their energy reserves, the level of competition, local weather or feeding conditions, etc. A reactive mechanism such as this, which allows the flexibility to respond to intrinsic and extrinsic cues, would also make it difficult for partners to coordinate the timing of their movements, because individuals are likely to differ in feeding efficiency, nutritional status, etc., all of which affect decision making. Indeed, there was no evidence for coordination of the timing of movements by partners.

Nonbreeding destinations were, however, much more similar within than between pairs. However, because they were not identical (Fig. 1a, see also Supplementary material), it is highly unlikely that pair members spend time together during the migration period, unless they coincide in the same area by chance. Also, the striking sex differences in both spatial and temporal aspects of the migration journeys that we observed in this population indicate that males and females actually have very different migration strategies (Müller et al., 2014). The few studies to date that have documented pair members of migratory species associating with each other during the migration period are of two species of migratory sea duck, in which partners were reported to reunite in nonbreeding areas (Ens et al., 1996), and in geese and swans, which have decades-long partnerships and family groups remain close throughout the year, including during migration (Ens et al., 1996). Our findings, in contrast, do not provide any evidence that shearwaters maintain a close pair bond during migration, even if partners are more likely than unpaired birds to spend the winter in the same region. Therefore, the proximate cause of the commonality between pair members in nonbreeding destination is much more likely to be a shared trait that influences individual choices about how far to travel, rather than any active coordination of activities. We therefore investigated several hypotheses relating to potentially shared traits that might explain similarities in nonbreeding destination among partners: (1) comparable body condition or size and (2) proximity of nest sites in the breeding colony, which may reflect similar genes or microenvironments.

\section{Body Condition and Size as Predictors of Migration Destination}

Birds in our study colony make very variable short- or longdistance migrations along the west coast of Africa (Müller et al., 2014), and individuals that travelled to the most southerly destinations incur three potential costs: (1) more time spent in flight, which is energetically demanding, (2) less time for feeding and resting in the nonbreeding areas, which has energetic repercussions, and (3) a later return to the breeding colony, which imposes a disadvantage in competition for nest sites (Ramos, Monteiro, Sola, \& Moniz, 1997), and can result in what have recently been described as 'carryover' effects: poorer breeding performance or forced breeding deferral until the following season (Catry, Dias, Phillips, \& Granadeiro, 2013). We also expect that the costs of reproduction associated with fledging its chick will deplete the adult's energy reserves, with potential impacts on its postbreeding migration. The recent study of Cory's shearwaters involved an experiment in which some birds were manipulated to invest less in reproduction: these individuals subsequently migrated less far and returned to the breeding colony sooner in the following spring compared with unmanipulated birds (Catry et al., 2013). Such effects may explain the similarities within pairs in migration distances that we observed. Given the costs associated with long-distance migration, birds appear to have a strong incentive to remain closer to the colony (but see Magnusdottir et al. 2014; Garthe et al. 2012). Little is known, however, about the factors that may influence a decision to travel further, which makes it make it difficult to formulate expectations a priori about whether birds in poor condition should remain closer to the colony or keep travelling south. Nevertheless, we assumed that the same factors may be important to both pair members, and investigated whether similarities in body size or condition could explain why they adopt a migration strategy in common. First, we tested whether pair members had similar nutritional reserves. This did not reveal any correlation among pair members in body mass or condition measured in mid chick rearing. The shearwaters that migrated the furthest south were those that had been heavier (Fig. 2), yet we found no association between migration behaviour and scaled body mass index, which in theory should be a better indicator of energy reserves. Nor was structural size a good predictor of migration behaviour, as we found no direct relationship between bill length and any spatial migration parameters. However, we did find that pair members with similar-sized bills tended to spend the nonbreeding period closer together, although the effect was weak. Although this is suggestive of some size-related latitudinal stratification of individuals during the nonbreeding period, the result would need to be confirmed with a larger sample.

Several hypotheses relating body size to migration behaviour actually predict that larger individuals have the luxury of choosing to migrate less far than smaller individuals (e.g. Ketterson \& Nolan, 1976; Gauthreaux, 1982), and therefore are able to reap the benefits of returning sooner to the breeding site. A previous study on Cory's shearwaters found no support for these hypotheses (Perez, Granadeiro, Dias, Alonso, \& Catry, 2014). Furthermore, larger birds in our study travelled further than smaller birds, which is in the opposite direction to the result predicted by the body size hypotheses. Regardless, mass during breeding did correspond with migration distance, although as there was no repeatability in mass within breeding pairs, it is unlikely to be the main mechanism underlying the similarities in migration destination. 
Influence of Nest Proximity on Migration Characteristics

The observed commonality in migration behaviour of pair members may also have arisen via a variety of mechanisms associated with proximity of their nest sites. Birds nesting close to each other are more likely to experience similar microenvironments (e.g. Mougin, 2000; Catry, Granadeiro, \& Oliveira, 2006). A recent study found an association between such nest characteristics and foraging movements of Cory's shearwaters during the breeding season (Werner, Paiva, \& Ramos, 2014), and potentially the same factors may also influence migration, resulting in some similarities among birds from the same nest cluster. Furthermore, in a spatially heterogeneous colony, nest clusters of better quality may attract higher quality breeding pairs, whereas poorer quality pairs may aggregate in less desirable sites. If adult quality influences migration behaviour, then this scenario should give rise to the same relationship between proximity of nest sites and similarities in migration behaviour. However, we found that birds from the same nest cluster were not more similar in terms of migration parameters than birds from different clusters. If associations with nest distances reflect variation in individual quality, these effects may in theory be mediated by body condition; however, we also found that birds from the same cluster were no more likely to be of similar body mass or condition than those from a different cluster.

Similarity in migration behaviour of pair members may also have arisen as a consequence of nonrandom mating, given the extremely high natal philopatry of this species, which results in recruitment to sites in very close proximity (usually $<100 \mathrm{~m}$ ) to the natal nest. Shearwaters also remain very faithful to their nest site; when forced to change, they rarely move $>100 \mathrm{~m}$ (Thibault, 1994) and if re-pairing occurs, this is often with neighbours (Mougin, 2000). Indeed, breeding pairs of Cory's shearwater are more closely related genetically than pairs selected at random (Rabouam, Bretagnolle, Bigot, \& Periquet, 2000). The genes they share could influence migration (Pulido, 2007). To assess whether potential genetic similarities among birds were associated with similarity in migration strategies, we compared neighbours (nest distances $<100 \mathrm{~m}$ ) with non-neighbours (nest distances $\geq 100 \mathrm{~m}$ ). The distances between nonbreeding areas of neighbours were smaller than those of non-neighbours, consistent with the pattern expected if the high philopatry leads to inbreeding within clusters. Given that nests were categorized depending on whether or not they were within $100 \mathrm{~m}$ of each other and, at this scale, heterogeneity in the landscape means that each 'neighborhood' includes numerous nests that vary greatly in quality, it seems that the quality of the individual nest site cannot explain the differences between neighbours and non-neighbours.

A link between nonrandom mating and migration patterns may also have arisen via additional mechanisms that we were unable to explore in our study, and which are not expected to be associated with nest distances. For example, pairs may have formed according to timing of return to the colony. Pair members did not seem to return at the same time in this study, but they might have when the pair first formed. As date of arrival at the breeding site reflects the nonbreeding destination, and as individuals are consistent in their migration strategies from year to year, nonrandom mating according to arrival date could result in similar migration destinations among partners. Little is known about when and how partnerships are formed in this species, but it is very unlikely that the similarities in migration patterns among partners could be because pairs form in nonbreeding areas (for which there is in any case no evidence), because of the strong philopatry observed in both sexes (Rabouam et al. 1998), which causes both pair members to breed in nests sites near their natal nest, and the strong tendency to mate with neighbours following divorce (Mougin et al., 2000).
Alternatively, as shearwaters tend to mate with birds of similar age (Bradley, Wooller, \& Skira, 1995; but see Mougin, 2000), and given the evidence for a change in migration strategy with life history stage (Peron \& Gremillet, 2013), conceivably, there may be cohort effects, or migration pattern may also change with age within individuals after recruitment. However, we have not yet monitored our study population for sufficient time to test this. In addition, birds may intentionally select mates that are more compatible in terms of other aspects of behaviour, and so similarities in migration destinations among partners may reflect similarities in general behavioural syndromes. Recently, studies have shown links between individual differences in behaviour in birds and movement patterns, including foraging behaviour (Patrick et al., 2014), as well as dispersal (e.g. Korsten, van Overveld, Adriaensen, \& Mattysen, 2013). This research has not yet been linked to migration strategies, although we are currently investigating this.

\section{Conclusion}

The evidence for similar migration behaviour among breeding partners in this study raises key questions about the underlying proximate causes. We present an intriguing result suggesting the underlying cause may be genetic relatedness, although this conclusion rests on the assumption that high natal philopatry leads to inbreeding within neighbouring nests. A genetic basis for some of the observed variation in migration strategies among pairs and individuals seems likely, given the consistent individual differences in migration patterns observed in shearwaters (e.g. Dias, Granadeiro, Phillips, Alonso, \& Catry, 2011; Müller et al., 2014; Yamamoto et al., 2014) and other birds (e.g. Vardanis, Klaassen, Strandberg, \& Alerstam, 2011), and recent work identifying genes associated with migration behaviour (Mueller, Pulido, \& Kempenaers, 2011). Furthermore, petrels do not learn migration routes from their parents but rely instead on an inherited endogenous program (Akesson \& Hedenstrom, 2007). If pairs indeed share genes influencing migration strategy, this results in a population in which the frequency of recessive homozygotes for alternative migration strategies increases more quickly than in a population with random mating, allowing more rapid adjustment to environmental changes. This has important ramifications for the ability of such species to adapt to anthropogenic change.

\section{Acknowledgments}

We thank Paolo Becciu for helping with fieldwork. Special thanks to Ken Yoda for comments on the manuscript and for support while it was written. Our research permit was provided by Regione Siciliana. The study was supported by Ornis Italica, Regione Siciliana and Assessorato Risorse Agricole e Alimentari with a grant to the Ringing Unit of Palermo and LIFE11 + NAT/IT/000093 'Pelagic Birds'. M.M. was funded by a JSPS postdoctoral fellowship.

\section{Supplementary Material}

Supplementary data related to this article can be found at http:// dx.doi.org/10.1016/j.anbehav.2015.02.005.

\section{References}

Akesson, S., \& Hedenstrom, A. (2007). How migrants get there: migratory performance and orientation. BioScience, 57, 123-133.

Bates, D., Maechler, M., Bolker, B., \& Walker, S. (2014). lme4: Linear mixed-effects models using Eigen and S4. $R$ package version 1.1-6. http://CRAN.R-project.org/ package $=$ lme4. 
Becciu, P., Massa, B., \& Dell'Omo, G. (2012). Body mass variation in Scopoli's shearwaters Calonectris diomedea breeding at Linosa Island. In P. Yesou, N. Baccetti, \& J. Sultana (Eds.), Ecology and conservation of Mediterranean Seabirds and other bird species under the Barcelona Convention - Proceedings of the $13^{\text {th }}$ Medmaravis Pan-Mediterranean Symposium (pp. 16-18). Alghero, Sardinia: Medmaravis.

Berthold, P. (2001). Bird migration (2nd ed.). Oxford, U.K.: Oxford University Press.

Black, J. M. (1996). Partnerships in birds: The study of monogamy. Oxford, U.K.: Oxford University Press.

Black, J. M. (2001). Fitness consequences of long-term pair bonds in barnacle geese: monogamy in the extreme. Behavioural Ecology, 12, 640-645.

Bradley, J. S., Wooller, R. D., \& Skira, I. J. (1995). The relationship of pair-bond formation and duration to reproductive success in short-tailed shearwaters Puffinus tenuirostris. Journal of Animal Ecology, 64, 31-38.

Bried, J., \& Jouventin, P. (2002). Site and mate choice in seabirds: an evolutionary approach. In E. A. Schreiber, \& J. Burger (Eds.), Biology of marine birds (pp. 263-305). Boca Raton, FL: CRC Press.

Cachia Zammit, R., \& Borg, J. (1986). Notes on the breeding biology of the Cory's shearwater in the Maltese Islands. Il-Merill, 24, 1-9.

Catry, P., Dias, M. P., Phillips, R. A., \& Granadeiro, J. P. (2013). Carry-over effects from breeding modulate the annual cycle of a long-distance migrant: an experimental demonstration. Ecology, 94, 1230-1235.

Catry, P., Granadeiro, J. P., \& Oliveira, P. (2006). Do Cory's shearwaters Calonectris diomedea synchronize laying among close neighbours? A reappraisal using data from artificial nest sites. Acta Ethologica, 9, 87-90.

Chardine, J. W. (1986). The influence of pair-status on the breeding behaviour of the kittiwake Rissa tridactyla before egg laying. Ibis, 129, 515-526.

Clutton-Brock, T. H. (1989). Mammalian mating systems. Proceedings of the Roya Society B: Biological Sciences, 235, 339-372.

Clutton-Brock, T. H. (1991). The evolution of parental care. Princeton, NJ: Princeton University Press.

Costantini, D., \& Møller, A. P. (2013). A meta-analysis of the effects of geolocator application on birds. Current Zoology, 59, 697-706.

Coulson, C. (1970). The influence of the pair bond and age on the breeding biology of the kittiwake gull, Rissa tridactyla. Journal of Animal Ecology, 35, 269-279.

Dias, M. P., Granadeiro, J. P. Phillips, R. A., Alonso, H., \& Catry, P. (2011). Breaking the routine: individual Cory's shearwaters shift winter destinations between hemispheres and across ocean basins. Proceedings of the Royal Society B: Biological Sciences, 278, 1786-1793.

Dias, M. P. Granadeiro, J. P. Phillips, R., Alonso, H., \& Catry, P. (2012). Do seabirds differ from other migrants in their travel arrangements? On route strategies of Cory's shearwater during its trans-equatorial journey. PLoS One, 7, e49376.

Ens, B. J., Choudhury, S., \& Black, J. M. (1996). Mate fidelity and divorce in monogamous birds. In J. M. Black (Ed.), Partnerships in birds: The study of monogamy (pp. 345-401). Oxford, U. K.: Oxford University Press.

Faraway, J. J. (2006). Extending the linear model with R: Generalized linear, mixed effects and nonparametric regression models. Boca Raton, FL: Chapman \& Hall CRC.

Fricke, H. W. (1986). Pair swimming and mutual partner guarding in monogamous butterflyfish (Pisces: Chaetodontidae): a joint advertisement for territory. Ethology, 73, 307-333.

Garthe, S., Ludynia, K., Huppop, O., Kubetzki, U., Meraz, J. F., \& Furness, R. W. (2012) Consequences for activity, thermoregulation and energy budgets of winter migration range by northern gannets. Marine Biology, 159, 1907-1915.

Gauthreaux, S. A., Jr. (1982). The ecology and evolution of avian migration systems. In D. S. Farner, \& J. R. King (Eds.), Avian biology (pp. 93-167). New York, NY Academic Press.

Guilford, T., Meade, J., Willis, J., Phillips, R. A., Boyle, D., Roberts, S., et al. (2009). Migration and stopover in a small pelagic seabird, the Manx Shearwater Puf finus puffinus: insights from machine learning. Proceedings of the Royal Society B: Biological Sciences, 276, 1215-1223.

Guilford, T., Wynn, R., McMinn, M., Rodríguez, A., Fayet, A., Maurice, L., et al. (2012) Geolocators reveal migration and pre-breeding behaviour of the critically endangered Balearic shearwater Puffinus mauretanicus, PLoS One, 7 e e33753.

Gunnarsson, T. G., Gill, J. A., Sigurbjornsson, T., \& Sutherland, W. J. (2004). Pair bonds - arrival synchrony in migratory birds. Nature, 431, 646.

Hamer, K. C., Schreiber, E. A., \& Burger, J. (2002). Breeding biology, life histories, and life history-environment interactions in seabirds. In E. A. Schreiber, \& J. Burger (Eds.), Biology of marine birds (pp. 217-261). Boca Raton, FL: CRC Press.

Hatch, S. A. (1990). Individual variation in behavior and breeding success of northern fulmars. The Auk, 107, 750-755.

Igual, J. M., Forero, M. G., Tavecchia, G., Gonzalez-Solis, J., Martinez-Abrain, A., Hobson, K. A., et al. (2005). Short-term effects of archibal tags on Cory's shearwater (Calonectris diomedea). Marine Biology, 146, 619-624.

Jovani, R., \& Tella, J. L. (2007). Fractal bird nest distribution produces scale-free colony sizes. Proceedings of the Royal Society B: Biological Sciences, 274, 2465-2469.

Ketterson, E. D., \& Nolan, V. J. (1976). Geographic variation and its climatic correlates in the sex ratio of eastern-wintering Dark-eyed Juncos (Junco hyemalis hyemalis). Ecology, 57, 679-693.

Korsten, P., van Overveld, T., Adriaensen, F., \& Mattysen, E. (2013). Genetic integration of local dispersal and exploratory behaviour in a wild bird. Nature Communications, 4, 2362
Kuznetsova, A., Brockhoff, P. B., \& Christensen, R. H. B. (2014). ImerTest: Tests for random and fixed effects for linear mixed effect models (lmer objects of lme4 package). $R$ package version 2.0-6. http://CRAN.R-project.org/package=lmerTest. Lessells, C. M., \& Boag, P. T. (1987). Unrepeatable repeatabilities: a common mistake. Auk, 104, 116-121.

Limmer, B., \& Becker, P. H. (2010). Improvement of reproductive performance with age and breeding experience depends on recruitment age in a long-lived seabird. Oikos, 119, 500-507.

Lo Valvo, M. (2001). Sexing adult Cory's shearwater by discriminant analysis of body measurements on Linosa Island (Sicilian channel), Italy. Waterbirds, 24, 169-174.

Magnusdottir, E., Leat, E. H. K., Bourgeon, S., Jónsson, J. E., Phillips, R. A., Strøm, H., et al. (2014). Activity patterns of wintering great skuas Stercorarius skua. Bird Study, 61, 301-308.

Massa, B., \& Lo Valvo, M. (1986). Biometrical and biological considerations on the Cory's Shearwater Calonectris diomedea. In Medmaravis, \& X. Monbailliu (Eds.), Mediterranean marine avifauna (pp. 293-313). Berlin, Germany: Springer.

Mills, J. A. (1979). The influence of age and pair bond on the breeding biology of the red-billed gull, Larus novaehollandiae scopulinus. Journal of Animal Ecology, 42, $147-162$.

Mougin, J. L. (2000). Pairing in the Cory's shearwater (Calonectris diomedea) of Selvagem Grande. Journal of Ornithology, 141, 319-326.

Mougin, J. L., Jouanin, C., \& Roux, F. (2000). Mate fidelity in Cory's shearwater Calonectris diomedea on Selvagem Grande. Ibis, 142, 421-427.

Müller, M. S., Massa, B., Phillips, R. A., \& Dell'Omo, G. (2014). Individual consistency and sex differences in migration strategies of Scopoli's shearwaters Calonectris diomedea despite year differences, Current Zoology, 60, 631-641.

Mueller, J. C., Pulido, F., \& Kempenaers, B. (2011). Identification of a gene associated with avian migratory behaviour. Proceedings of the Royal Society B: Biological Sciences, 278(1719), 2848-2856.

Nakagawa, S., \& Schielzeth, H. (2010). Repeatability for Gaussian and non-Gaussian data: a practical guide for biologists. Biological Reviews, 85, 935-956.

Ochi, D., Oka, N., \& Watanuki, Y. (2010). Foraging trip decisions by the streaked shearwater Calonectris leucomelas depend on both parental and chick state. Journal of Ethology, 28, 313-321.

Ollason, J. C., \& Dunnet, G. M. (1988). Variation in breeding success in fulmars. In T. H. Clutton-Brock (Ed.), Reproductive success. Studies of individual variation in contrasting breeding systems (pp. 263-278). Chicago, IL: University of Chicago Press.

Patrick, S. C., Bearhop, S., Gremillet, D., Lescroel, A., Grecian, W. J., Bodey, T. W., et al. (2014). Individual differences in searching behaviour and spatial foraging consistency in a central place marine predator. Oikos, 123, 33-40.

Peig, J., \& Green, A. J. (2009). New perspectives for estimating body condition from mass/length data: the scaled mass index as an alternative method. Oikos, 118, 1883-1891.

Perez, C., Granadeiro, J. P., Dias, M. P., Alonso, H., \& Catry, P. (2014). When males are more inclined to stay at home: insights into the partial migration of a pelagic seabird provided by geolocators and isotopes. Behavioral Ecology, 25, 313-319.

Peron, C., \& Gremillet, D. (2013). Tracking through life stages: adult, immature and juvenile autumn migration in a long-lived seabird. PLoS One, 8, e72713.

Phillips, R., Silk, J., Croxall, J., Afanasyev, V., \& Briggs, D. (2004). Accuracy of geolocation estimates for flying seabirds. Marine Ecology Progress Series, 266, 265-272.

Phillips, R. A., Silk, J. R. D., Croxall, J. P., Afanasyev, V., \& Bennett, V. J. (2005). Summer distribution and migration of nonbreeding albatrosses: individual consistencies and implications for conservation. Ecology, 81, 2386-2396.

Pulido, F. (2007). The genetics and evolution of avian migration. BioScience, 57, 165-174.

Rabouam, C., Bretagnolle, V., Bigot, Y., \& Periquet, G. (2000). Genetic relationships of Cory's shearwater: parentage, mating assortment, and geographic differentiation revealed by DNA fingerprinting. Auk, 177, 651-662.

Rabouam, C., Thibault, J. C., \& Bretagnolle, V. (1998). Natal philopatry and close inbreeding in Cory's shearwater (Calonectris diomedea). Auk, 115, 483-486.

Ramos, J. A., Monteiro, L. R., Sola, E., \& Moniz, Z. (1997). Characteristics and competition for nest cavities in burrowing nesting Procellariiformes. Condor, 99, 634-641.

Rayner, M. J., Taylor, G. A., Gummer, H. D., Phillips, R. A., Sagar, P. M., Shaffer, S. A., et al. (2012). The breeding cycle, year-round distribution and activity patterns of the endangered Chatham petrel (Pterodroma axillaris). Emu, 112, 107-116.

Ricklefs, R. E. (1984). Meal sizes and feeding rates of Christmas shearwaters and phoenix petrels on Christmas Island, Central Pacific Ocean. Ornis Scandinavica, $15,16-22$

Sánchez-Macouzet, O., Rodríguez, C., \& Drummond, H. (2014). Better stay together: pair bond duration increases individual fitness independent of age-related variation. Proceedings of the Royal Society B: Biological Sciences, 281(1786), 20132843. http://dx.doi.org/10.1098/rspb.2013.2843.

Sangster, G., Collinson, J. M., Crochet, P. A., Knox, A. G., Parkin, D. T., \& Votier, S. C. (2012). Taxonomic recommendations for British birds: eighth report. Ibis, 154, $874-883$.

Seibt, U., \& Wickler, W. (1979). The biological significance of monogamy in the shrimp Hymenocera picta. Zeitschrift für Tierpsychologie, 50, 166-179.

Shaffer, S., Tremblay, Y., Weimerskirch, H., Scott, D., Thompson, D. R., Sagar, P. M., et al. (2006). Migratory shearwaters integrate oceanic resources across the Pacific Ocean in an endless summer. Proceedings of the 
National Academy of Sciences of the United States of America, 103, 12799-12802.

Swatschek, I., Ristow, D., \& Wink, M. (1994). Mate fidelity and parentage in Cory's shearwater Calonectris diomedea - field studies and DNA fingerprinting. Molecular Ecology, 3, 259-262.

Thibault, J. C. (1994). Nest-site tenacity and mate fidelity in relation to breeding success in Cory's Shearwater Calonectris diomedea. Bird Study, 41, 25-28.

Van de Pol, M., Heg, D., Bruinzeel, L. W., Kuijper, B., \& Verhulst, S. (2006). Experimental evidence for a causal effect of pair-bond duration on reproductive performance in oystercatchers (Haematopus ostralegus). Behavioural Ecology, 17, 982-991.

Vardanis, Y., Klaassen, H. G., Strandberg, R., \& Alerstam, T. (2011). Individuality in bird migration: routes and timing. Biology Letters, 7, 502-505.
Werner, A. C., Paiva, V. H., \& Ramos, J. A. (2014). On the 'real estate market': individua quality and the foraging ecology of male Cory's shearwaters. Auk, 131, 265-274.

Wittenberger, J. F., \& Tilson, R. L. (1980). The evolution of monogamy: hypotheses and evidence. Annual Review of Ecology and Systematics, 11, 197-232.

Yamamoto, T., Takahashi, A., Katsufumi, S., Oka, N., Yamamoto, M., \& Trathan, P. N. (2014). Individual consistency in migratory behaviour of a pelagic seabird Behaviour, 151, 683-701.

Yamamoto, T., Takahashi, A., Oka, N., Iida, T., Katsumata, N., Sato, K., et al. (2011). Foraging areas of streaked shearwaters in relation to seasonal changes in the marine environment of the Northwestern Pacific: inter-colony and sex-related differences. Marine Ecology Progress Series, 424, 191-204. 